\title{
O processo de produção de vitrais sob a ótica da tradição
}

Mariana G. Wertheimer*

Margarete R. F. Gonçalves ${ }^{* \star}$

\section{Resumo}

Não se pode falar em vitral sem responder a aspectos de conceitos de tradição. $O$ processo de trabalho manual que envolve a produção vitral baseia-se na memória contida no conhecimento transmitido de geração a geração, que a pratica de atelier pouco mudou, visto que a fabricação do vitral está basicamente vinculada ao seu processo de obtenção. A justaposição de vidros, coloridos ou não, e uma calha de chumbo é que define a produção do vitral e esse processo se encontra amadurecido desde a Idade Média. Esta arte não chegaria aos dias de hoje se não houvesse a memória e a tradição desta prática artesanal, originária de uma hierarquia formada por mestres e aprendizes. Focado na visão de que a memória e a tradição são fontes de identidade cultural e patrimonial, no presente trabalho, fez-se um estudo sobre o processo histórico, artesanal e tecnológico de produção de vitrais e seu estreito vínculo com o saber e a tradição. Refletiu-se, também, sobre a tradição e os aspectos de inovação e continuidade do processo de produção de vitrais.

Palavras-chave: Vitrais. História dos vitrais. Preservação do patrimônio cultural.

\section{The process of stained glass manufacture of tradition vision}

\begin{abstract}
It's impossible to make a discussion about stained glass without bringing up the concepts of tradition. The manual process of stained glass manufacture is based on the knowledge transmitted from generation to generation, and this process has changed just a little until today. The overlaps of glasses colored or not in the plumb gutter define the production of stained glass and this manufacture process is a wellknown process since the middle age. This kind of artisanal technique would not remain to date if there were no memory and tradition to use this practice. Such practice originates from the hierarchic relationship of masters and apprentices.
\end{abstract}


Concentrating on the vision that the memory and tradition are fonts of a cultural and patrimonial identity, this work studied the historical, artisanal and technological process of stained glass manufacture and their close link with the tradition and the knowledge. We also reflected about innovation and continuity of the process of stained glass production.

Key-words: Stained glass. Stained glass history. Preservation of cultural heritage.

\section{Introdução}

Nos últimos vinte e cinco anos do século 20 aspectos relacionados aos temas memória e tradição têm sido um expoente, cada vez maior, de interesse em diversas áreas da ciência. São olhares e conceitos diversos, interdisciplinares e multifocais, que mostram a ligação entre a memória e a tradição.

Segundo Candau (2002, p.5), sem a memória e a tradição vive-se unicamente o momento, não se faz conexões conceituais ou cognitivas, não se criam vínculos e, consequentemente, não se criam identidades históricas. O autor ressalta que sem a memória as relações sociais não se dão, não são criados pactos e não é possível a transmissão de uma tradição, de uma cultura. As várias áreas de conhecimento apresentam pareceres que auxiliam na valorização destes conceitos.

A ligação entre a memória e a tradição é muito estreita e uma delas se relaciona ao fato de que ambas funcionam no movimento de manutenção das "características" do passado (ORNELLAS, 2003).

Quando se fala em tradição como instrumento de memória levamos em conta seu aspecto dialético e não metafísico. Considera-se, portanto, a transmissão de saberes e formas de fazer do passado da atividade humana criadora, e não uma resultante de uma revelação divina ou mística. Sendo assim, trata-se de um processo seletivo de interpretação e valorização cultural, resultante da ação humana, onde cada grupo social constrói suas tradições, interpretando e se apropriando do passado de acordo com perspectivas e interesses efetivamente 
definidos pelas relações sociais existentes. Isto resulta na manutenção do caráter ideológico e de formação cultural da tradição (COUTINHO, 2005). (1).

A tradição, em geral, é especifica de cada grupo, é particular, mas não exclusiva. Esta resulta de um processo dialético de continuidade, inovação e adaptação sóciocultural (AREVALO, 2001).

De acordo com Ornellas (2003), a tradição oral parece ser o melhor espaço para se pensar nas relações memória e tradição. O autor ressalta que a tradição oral estabelece uma relação direta, que se configura como um fio que se enreda como uma malha de referências que é a tradição. Em seu texto "As Malhas do Tempo Identitário", ele descreve:

[...] a memória dos homens possui uma capacidade criativa que ultrapassa a simples função de arquivo, de banco de dados, de repositório de imagens. Por sobre e para alem dessas funções, a memória é criação de novos sentidos, é a repetição do mesmo em diferença, distorção especular de um dado.

Como relata Eduardo Granja Coutinho (2005, p. 2), em seu artigo Os sentidos da tradição (2), a tradição é a designação de um legado cultural, ou se preferirmos, de um objeto ou produto da atividade humana que se reproduz e transmite no tempo, por meio de um processo socialmente elaborado.

No presente trabalho, focado na visão de que a memória e a tradição são fontes de identidade cultural e patrimonial, fez-se um estudo sobre o processo de produção de vitrais e seu estreito vínculo com o saber, a partir de abordagens ligadas à memória e suas implicações no processo de manufatura, refletido na tradição e nos aspectos de inovação e continuidade do processo.

\section{A Produção Vitral e a Tradição}

A arte vitral é uma tradição milenar cuja transmissão de conhecimento foi baseada na pratica do fazer, no qual os processos da manufatura, em sua maioria, foram repassados sob forma oral, familiar e, também, através de alguma documentação escrita. 
Segundo Vieira (1996, p. 3), a primeira documentação europeia que registra e descreve, detalhadamente, os procedimentos usados na fabricação do vidro e do vitral é o tratado "Shedula diversarum artiium" de Teófilo (século 12). Além desta, outras fontes de conhecimento também são destaque, tais como: "De coloribus et artibus romanoru" de Heráclio; "Memória" de Antônio de Pisa (século 14); o "Libro dell'arte" de Cennino Cennini (século 15) e, ainda, "L'Art de la priture sur veire et de la vitreire" de Pierre Lê Vieil que recolheu todas as receitas vigentes durante o século 17 .

Considerando os conceitos de tradição de Arévalo (2001, p. 926), percebe-se que a arte vitral é uma tradição porque faz parte de uma cultura com "função de uso" que contém os saberes do passado e as transformações e adaptações da manufatura do presente. Pode-se dizer, então, que a produção vitral é uma tradição com dialética de oposição binária e complementar entre o passado e o presente, entre a continuidade e a mudança. $\mathrm{O}$ autor enfatiza ainda que "o continuar sem renovar significa repetir e o inovar necessita sempre o suporte do passado". Para Arévalo repetir sem a réplica do tempo é perder contato com a realidade.

Pensando na tradição como um ritual que pode se transformar continuamente, integrado em um processo inacabado de criação e recriação, o estudo da produção de vitrais inicia-se a partir da evolução do principal material utilizado na sua manufatura, o vidro.

O vidro, inicialmente soprado em manga ou coroa, a partir da revolução industrial, evoluiu para um processo de obtenção mecânica caracterizado por uma regularidade de composição e propriedades, variação de cores e para o uso de placas com dimensões cada vez maiores. $O$ uso de fornos industriais permitiu a produção em grande escala de vidros coloridos e o emprego do rolete (3) e, muitas vezes, da serra elétrica, instrumentos que substituíram o ferro quente usado para o corte, possibilitaram maior precisão e complexidade. 
No entanto, em detrimento da evolução do vidro, o processo de manufatura de vitrais permaneceu quase que inalterado, e os artistas envolvidos, denominados vitralistas, na condição de artesãos.

Considerando as reflexões de Ornellas (2003), que transcrevem que a manutenção do "espírito" do passado, que é a tradição, pressupõe um centro de identidade em torno do qual elementos se movimentam sem, necessariamente, alterar qualquer configuração, verifica-se que este processo se materializa no caso dos vitralistas, visto que estes mantêm aproximações às estruturas de organização de trabalho medieval, definidas por corporações e guildas. (4).

No período Medieval, o ofício do vitralista era feito em um sistema de corporações artesanais onde o aprendizado iniciava-se somente aos dez anos de idade e durava de quatro a dez anos, em uma relação de mestre - aprendiz. Vinculado aos padrões do período, só era admitido um aprendiz por vez em cada uma das corporações e o segundo só era aceito quando o primeiro já tivesse completado os quatro anos de aprendizagem. Durante este período, normalmente, a produção não era assinada pelos Mestres e as atividades eram todas manuais.

O estatuto de mestre só poderia ser adquirido após a execução final de um painel chamado de "obra de mestre", produzido com cortes especiais e, inclusive, várias incrustações (VIEIRA, 1996, p. 10).

A tradição do cerne de construção do oficio do vitralista e de um ateliê de vitral era, normalmente, passada para membros de uma mesma família. Antropologicamente falando, as gerações através do tempo que, pela repetição do oficio, transmitiam o conhecimento da produção do vitral.

Esta manutenção de características do passado, certamente, mudava um pouco de atelier para atelier, mas a estrutura básica permanecia a mesma.

Mantendo a estrutura medieval, no século 20, em alguns ateliês o trabalho ainda se manteve em hierarquia. Os pintores mais habilidosos eram encarregados da pintura de figuras humanas (rostos e corpos) e do planejamento do painel. As imagens de 
fundo podiam ser feitas por um aprendiz ou um pintor que não possuía tanta destreza. As atividades de cortes, montagem e calafetagem dos vidros eram feitas por artesãos e, por serem mais grosseiras e provocarem mais sujidades, normalmente, ficavam localizados separadamente do setor de pintura.

As diferenças entre os ateliês estavam na inovação das ferramentas, que permitiam maior produção e aumento na quantidade de profissionais, e em pequenas particularidades ligadas à tecnologia de produção de grisalhas.

De acordo com Mello (1996, p. 12), no ateliê Casa Conrado, existente na cidade de São Paulo, Brasil, desde 1889, as tarefas eram muito organizadas e intensificadas em função da quantidade de encomendas. A autora cita a existência de cartazes no ateliê que orientavam os funcionários sobre os serviços essenciais para a execução de um vitral. Nestes percebe-se que alguns produtos e tecnologias mudaram, mas o processo de execução é, praticamente, o mesmo da Idade Média. Nos cartazes liase:

Os dez serviços essenciais na execução de um bom vitral são:

1- Projeto Artístico

2.- Ampliação do projeto para escala real, marcando bem as linhas de chumbo

3 - Decalaque (5) sobre papel cartão e recorte dos moldes

4- Seleção dos vidros de cores e recortes deles com diamante, conforme moldes.

5- Montagem provisória e pintura de detalhes

6- Fixação da pintura em elevada temperatura em forno ou mufla

7- Montagem do vitral e ligações das peças de vidro por meio de baguetes de chumbo

8- Os chumbos são soldados e estanhados

9- As peças do Vitral são emassadas e calafetadas

10- Colocação final nos caixilhos na obra (MELLO, 1996, p. 145)

Como pode-se ver, a tradição serve de ponto de partida como quadro de referências às práticas nos ateliês de vitral do século $X X$, onde o desenho e a imitação dos pintores de cavalete era uma prática constante.

Outro aspecto que evidencia a manutenção da tradição dos vitrais e a produção de cartões (6) pelos ateliês do século 20, manufatura comum do vitral europeu desde o 
século 15. Como exemplo, cita-se o ateliê Casa Genta, existente na cidade de Porto Alegre, período de 1906 a 1998, onde o uso do cartão era uma constante, tendo em vista que alguns projetos (desenhos) se repetiam com adaptações apenas nas dimensões para o espaço a ser colocado.

Na produção de vitrais, as várias adaptações e mudanças no desenho do cartão, no decorrer dos séculos, facilitaram o processo mais delicado da execução de um vitral que é a pintura.

No Renascimento, o cartão era feito sobre uma tábua de madeira, geralmente o dobro do tamanho do painel final. O desenho era feito em escala real sobre a metade da tábua revestida de gesso por meio de um estilete. A partir do século 15 os cartões eram desenhados em tecido ou pergaminho, que mais tarde foram substituídos pelo papel (Figura 1) ou cartão, produtos até hoje utilizados (VIERA, 1996, p. 5). 


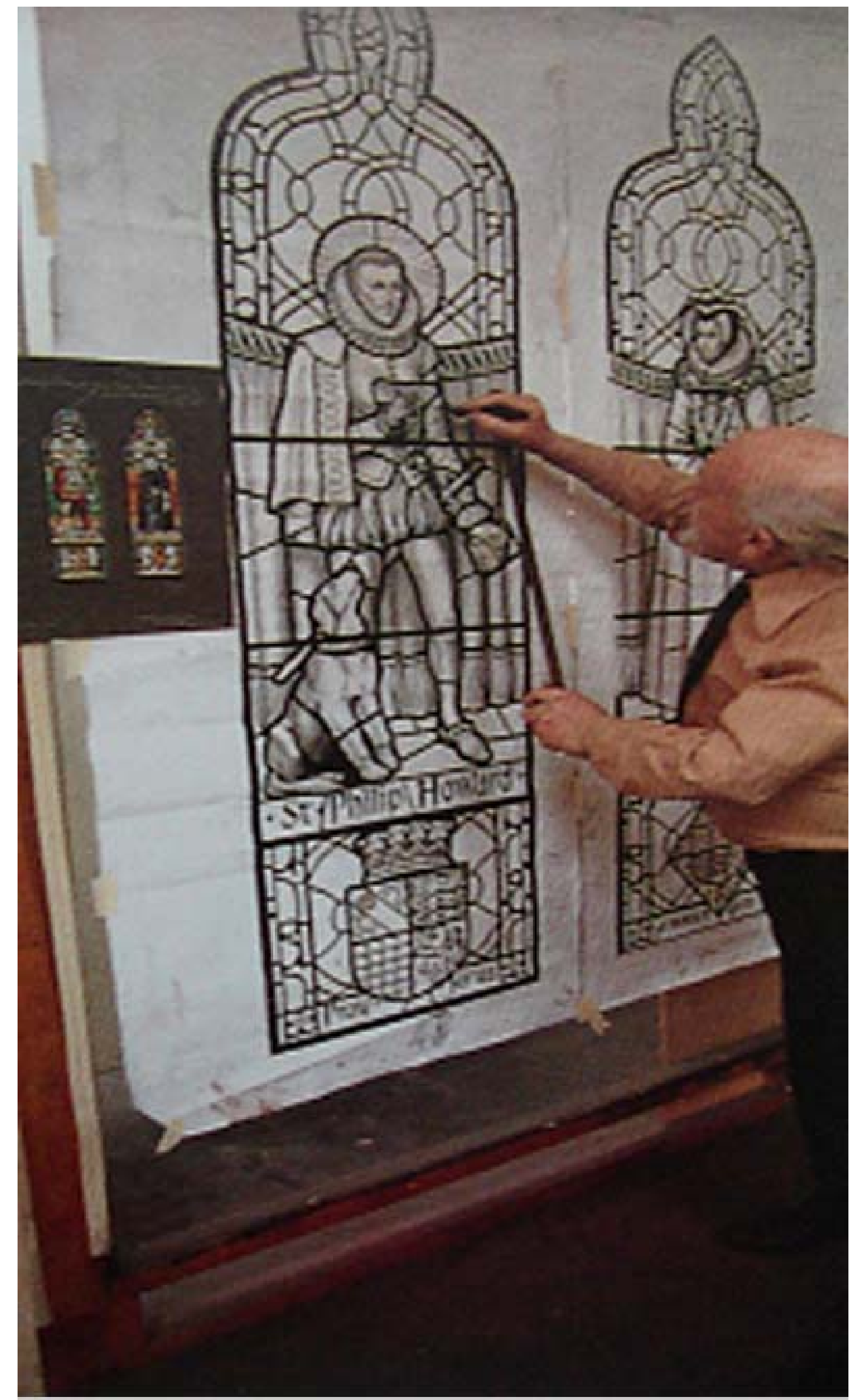

FIGURA 1 - Exemplo de um cartฐo desenhado em papel. Fonte: MORRIS, Elizabeth, 1987, p. 17. 
Conforme registros encontrados no ateliê Casa Conrado a ampliação do desenho era feita pelo processo de quadricular a figura a ser ampliada (Figura 2), fazendo parte de sua prática o uso de projeção na parede para facilitar o processo. Atualmente, muitos ateliês se utilizam da informática com programas específicos para a produção dos desenhos. No entanto, independente do suporte, o desenho depois de pronto é passado para um papel mais firme, visto que servirá de molde para o corte dos vidros.

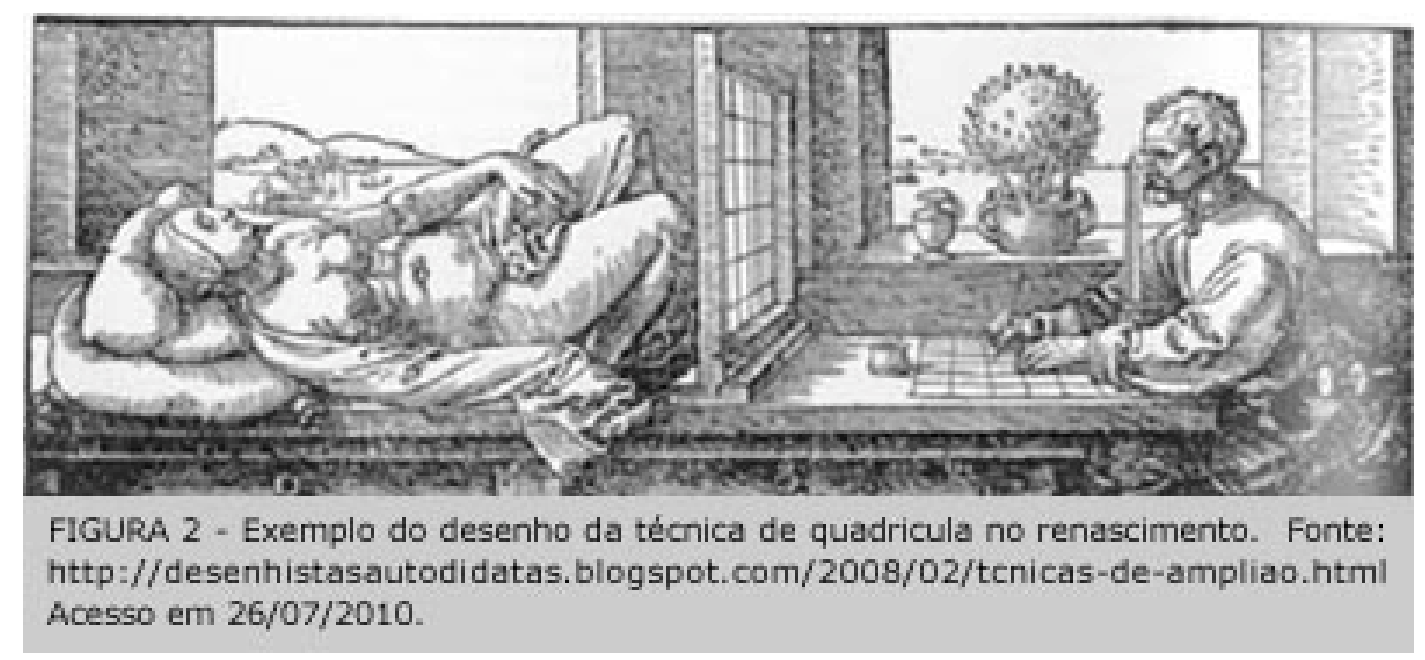

No sistema tradicional de corte dos cartões, conforme registros encontrados no processo de produção da Casa Genta (anos 1940), eram descontados 2 mm na periferia do desenho e $4 \mathrm{~mm}$ entre os espaços de vidro para o espaço da calha, feita em chumbo. Atualmente, para o corte dos cartões existem tesouras especializadas que descontam a espessura da alma da calha (Figura 3). Para facilitar o corte e a montagem do painel, os desenhos dos cartões têm suas divisões numeradas, conforme os pedaços de vidro e suas cores. 


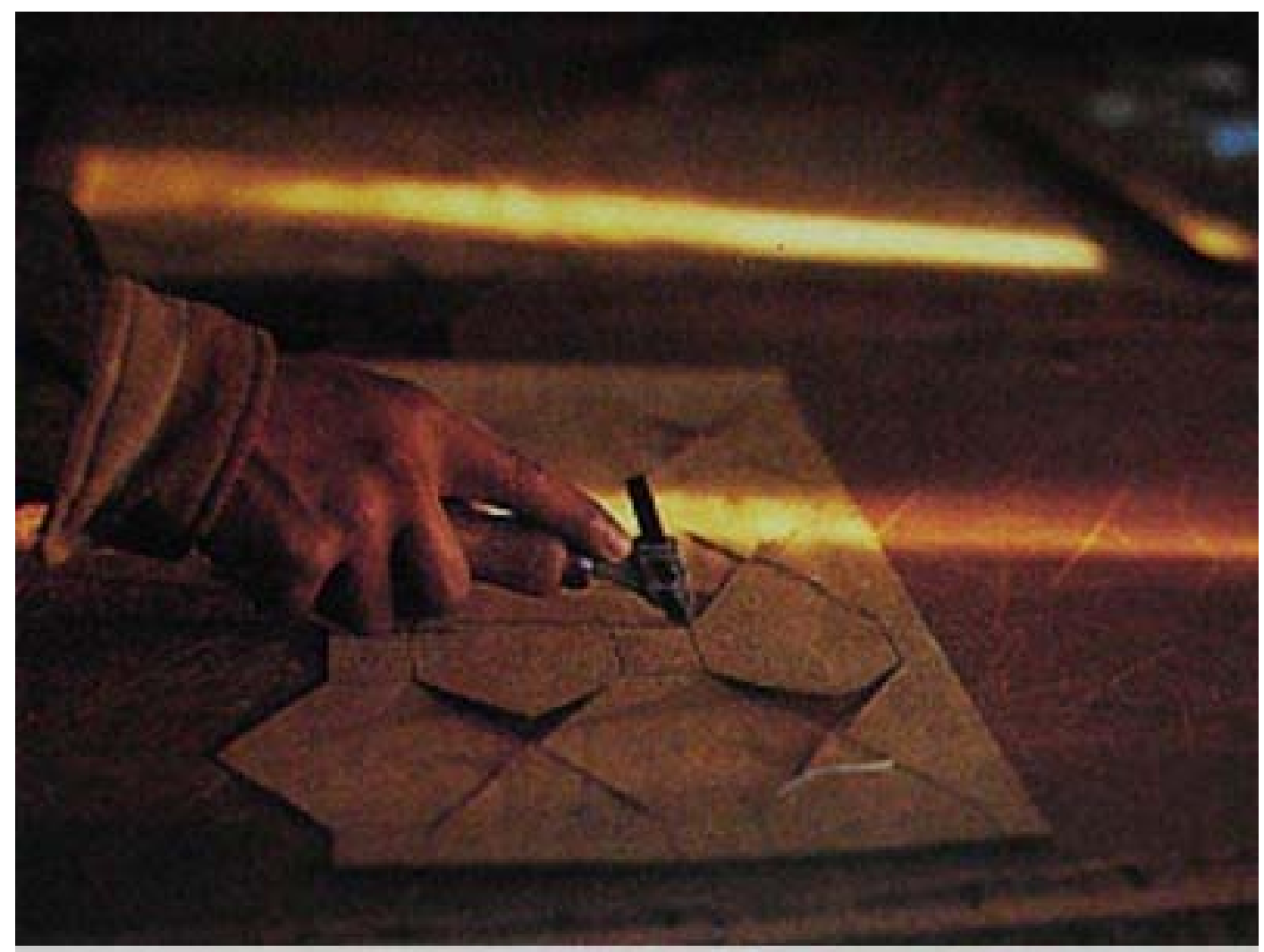

FIGURA 3 - Corte moderno do Cartão sem a espessura da alma da calha. Fonte: BRANDÃO, 1994 , p. 25.

Conforme Mello (1996) tem-se a noção da manutenção da tradição vidreira europeia na qualidade do vitral pela variação de cores e qualidades de texturas empregadas. Em seu trabalho ela relata:

[...] os vidros mais utilizados no ateliê eram o antique: macio, cheio de bolinhas em seu interior, de espessura irregular, era o mais apreciado pelos vitralitas. O catedral (preferencialmente alemão, mas que poderia ser belga ou francês) bastante usado porém com uma gama de cores um pouco restrita tem uma textura leve que the tira um pouco do brilho. O ártico (alemão) um vidro grosso muito bonito, mas muito duro, difícil de cortar, de trabalhar as curvas é bem brilhante e resistente ao forno. O plaqué, que foi importado em cores bem limitadas era um vidro resultante da união de duas ou mais placas de uma única cor, em uma placa de vidro incolor que usava para fazer trabalhos com ácido. Todos estes vidros podiam também passar por processos de jateamentos, gravações e oxidações. (MELLO, 1996, p. 152).

No Brasil a produção de vitrais foi pautada na importação de vidros, visto que a indústria nacional vidreira não tinha grande opção de vidros pigmentados. Registros encontrados no ateliê Casa Conrado, mostram que este possuía um estoque de 
vinte a trinta cores diferentes, as quais eram escolhidas em catálogos e encomendadas. Os fornecedores principais eram: França, Alemanha, Bélgica e EUA (MELLO, 1996). Já o ateliê Casa Genta, segundo o depoimento de Diego Pufal (7) importava, inicialmente, vidros coloridos da Bélgica e da Inglaterra e, posteriormente, da cidade de São Paulo, Brasil, da empresa de Vicente Cracasso (WERTHEIMER, 2009). (8).

A tradição de montar o painel de vidro a partir da modelagem das formas, tirando a transparência do vidro e quebrando a intensidade de luz, é o conceito básico do vitral que remonta às suas origens. O saber fazer deste conceito é o que diferencia, em sua plenitude, o fazer artesanal da manifestação artística.

Nesta etapa, o vitralista se diferencia do pintor de cavalete porque nos vitrais o artista modela a luz. Para isto, desde as suas origens, usa-se no vitral um pigmento que se chama grisalha, composto de óxidos metálicos, e um ligante que na Idade Média era urina, depois foi substituído por vinho e, atualmente, é utilizado vinagre, água ou álcool. Pela qualidade da pintura é que se identifica a qualidade do vitral. Os recursos no processo pictórico mudaram, mas a finalidade ainda é a mesma: a modelagem da luz.

Vieira (1996, p. 6) descreve em sua publicação os diferentes recursos usados na pintura à grisalha no transcorrer da história do vitral, como relatado abaixo:

\footnotetext{
"Como escreveu Teófilo: Toma um bocado de cobre e bate-o bem fino, queima-o num pequeno prato de ferro até ficar totalmente pulverizado. Pega em alguns pedacitos de vidro verde e de vidro azul-grego esfregando-os, separadamente, entre duas pedras porfírias. Mistura três produtos de modo que haja um terço de cada um. Desfá-los com cuidado nessa mesma pedra com vinho ou urina, coloca-os num vaso de ferro ou de chumbo e pinta com todo o cuidado, consoante os traços que estão na tábua. Se quiseres desenhar letrasno vidro cobre todas as partes com a mesma cor e escreve-as com a pinta do pincel". Uma outra receita de Chistophe Greiser (1565), guardada na biblioteca de Trèves, prova a preferência da grisalha de ferro à grisalha de cobre pelos pintores da Alemanha Meridional, os do Brabante e os Franceses... Também H. Schmitz notou a grisalha "avermelhada e granulada" dos vitrais de Colônia e a grisalha negra e plástica de outros vitrais alemães e suíços. (VIEIRA, 1996, p. 6)
} 
A tradição continuada e evolutiva na produção dos vitrais é fortemente identificada nas camadas pictóricas onde pode ser observado o desenvolvimento das técnicas de aplicação de grisalha, pintura sobre a superfície do vidro. Tais fatos podem ser constatados quando se compara a pintura do século 12 do painel da Cabeça de Cristo (Figura 4), originário de Wissembourg, Alascia, com a pintura do painel da imagem de São Pedro (Figura 5), existente na Igreja de São Pedro, Porto Alegre, RS, executada pelo mestre Maximiliano Dobmeier na década de 40 do século 20 , ateliê Casa Genta (WERTHEIMER, 2009). 


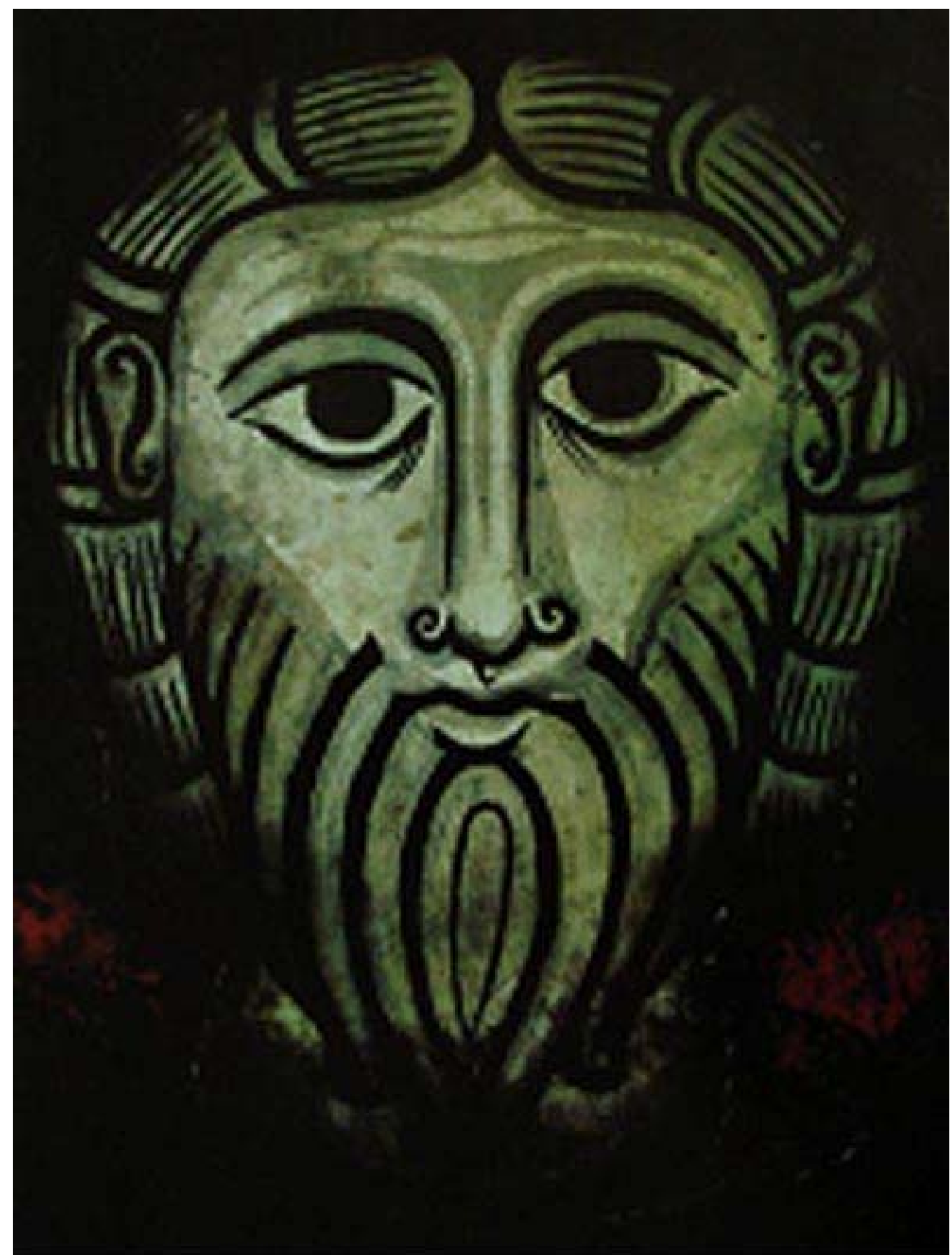

FIGURA 4 - Cabeça de Cristo de Wissembourg, Alsacia, Musée do L'Oeuvre NotreDame de Strasbourg Fonte: BRISAC 1996, p. 9 


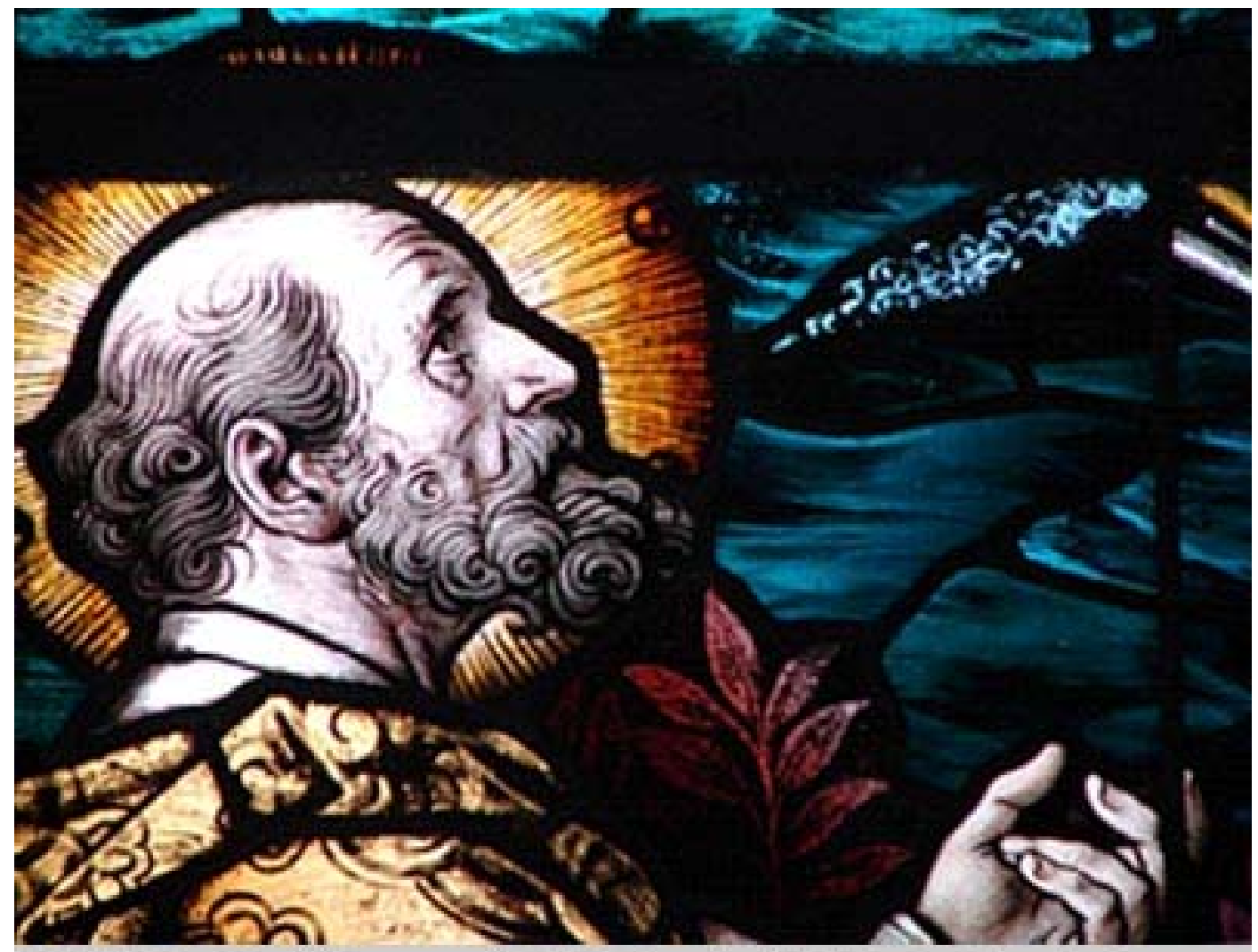

FIGURA. 5 - Painel da imagem de São Pedro, seculo XX. Fonte: Fernanda Barroso, 2009.

A técnica de execução da grisalha no painel da Cabeça de Cristo implica no emprego de três camadas, sendo a primeira aguada para recobrir todo o vidro, a segunda aguada para definir as sombras e, por último, um traço espesso feito com pincel para delinear os detalhes do desenho (BRISAC, 1986, p. 14).

$\mathrm{Na}$ imagem de São Pedro se constata na técnica de execução da grisalha uma maior sutileza na luminosidade e no modelado, com mais graduações de luzes que formam um desenho mais natural. Esta técnica, que remonta de uma prática usada no final da Idade Média e durante todo o Renascimento, implica no uso do ponteado feito com um pincel duro sobre a grisalha estendida para modelar as formas e detalhes do desenho (VIEIRA, 1996, p. 7).

A colocação de goma arábica na mistura da grisalha com o vinagre permite maior trababilidade da pintura. $\mathrm{O}$ uso da goma arábica permite que camadas pictóricas possam ser colocadas umas sobre as outras porque impede a remoção da camada anterior e evita a necessidade de queimas intermediárias. 
Em relatos de Mello (1996, p. 156), nas informações sobre os processos de grisalhas feitos no ateliê Casa Conrado, lê-se que era usado um pó (uma mistura de corantes minerais, óxidos de ferro e limalha de cobre diluído em água) aplicado com pincel, esponja de nylon ou, ainda, chumaços de algodão.

A queima da camada pictórica, na Idade Média, era feita em fornos abertos construídos no interior dos ateliês, nos quais as peças eram colocadas sobre um tabuleiro de ferro coberto com cal, necessitando de separadores para impedir a sua aderência durante o processo de fixação, e queimadas à temperaturas de $600^{\circ} \mathrm{C}$, aproximadamente. Estes separadores eram feitos com greda em pó, espécie de barro muito macio (VIEIRA, 1996, p. 7).

A tradição de queima das camadas pictóricas pode ser constatada em registros encontrados no ateliê Casa Genta, onde estas eram feitas em fornos fechados também sobre tabuleiros metálicos (Figura 6). Atualmente, nos fornos utilizados, as placas de cerâmica refratária substituem as placas metálicas garantindo uma maior planificação da superfície.

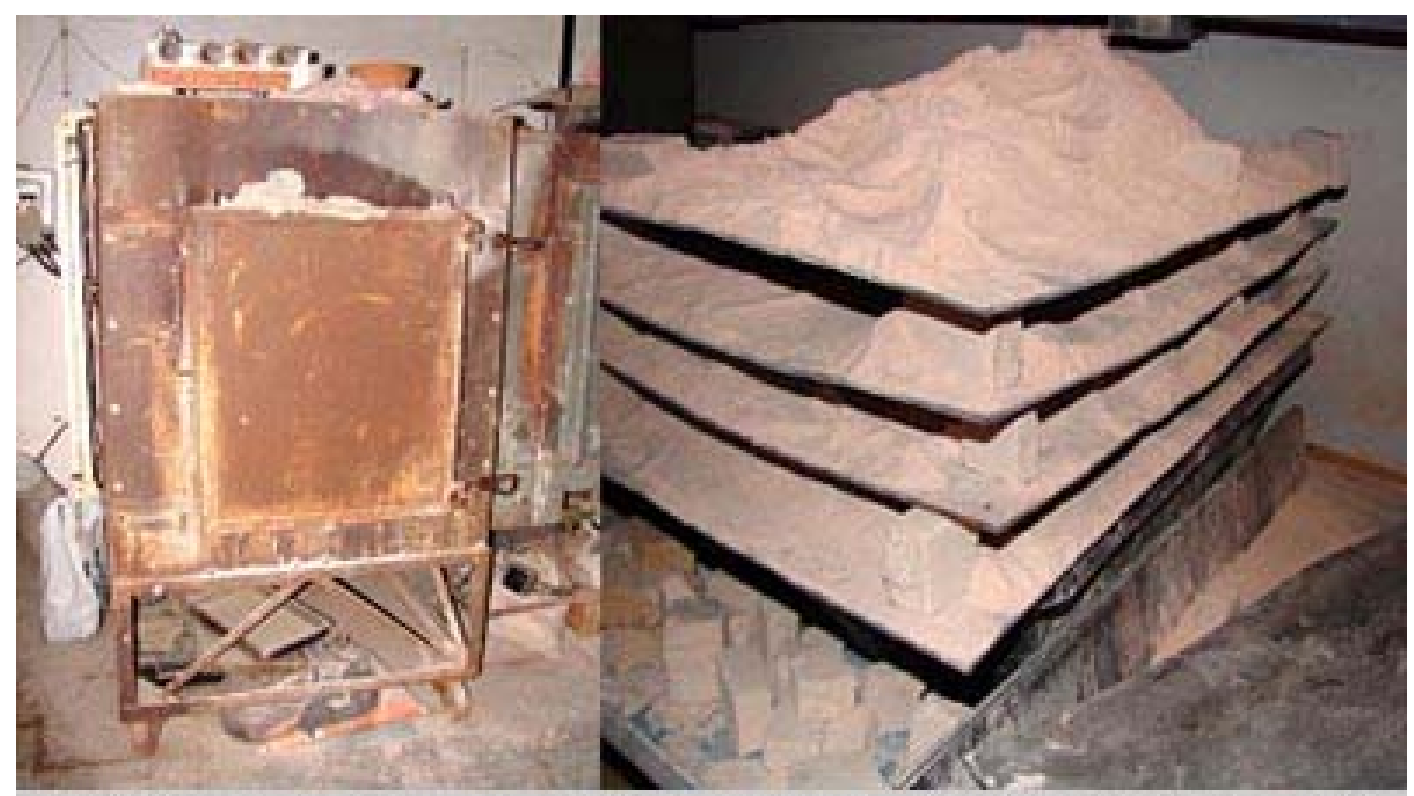

FIGURA 6 - Forno e tabuleiros metálicos usados pela Casa Genta, Porto Alegre-RS. Fonte: autora, maio 2009 
Sobre a ótica da tradição na produção pode-se identificar a origem, época, autor e estilo do processo utilizado a partir das características da camada pictórica. Por exemplo, pela pincelada e traço da grisalha pode-se identificar a origem de muitos vitrais.

Além da grisalha, outros materiais conferem efeitos cromáticos na superfície do vidro, tais como o amarelo de prata e os esmaltes. A pintura com amarelo de prata era usada desde a Antiguidade na decoração de objetos de vidro. Nos vitrais, entretanto, o amarelo de prata passou a ser utilizado a partir do ano 1300, permitindo uma nova coloração na placa de vidro incolor, indo de uma gama do amarelo limão ao laranja e ao âmbar.

O amarelo de prata é uma pintura aplicada na face exterior do vidro, produz manchas e sua temperatura de queima é de $500^{\circ} \mathrm{C}$ (MELLO, 1996).

O processo de produção das calhas metálicas, em perfil $\mathrm{H}$, usadas na conformação dos vitrais, sofreu poucas alterações. Inicialmente, era fundido o metal, uma combinação de chumbo e estanho, diretamente nas lingoteiras (Figura 7) que davam as calhas o seu formato final. Posteriormente, no século 15, as lingoteiras foram substituídas por fieras (9), que possibilitaram o ajuste de dimensões da alma (parte interna da calha) e das abas (partes externas na calhas) e trouxeram ao desenho do vitral novas expressividades através da variada espessura das calhas. As fieras, inicialmente, manuais (Figura 8) foram substituídas por elétricas (Figura 9), que aceleraram e facilitaram o trabalho com o ajuste das dimensões das calhas. Este processo se encontra muito bem descrito nos apontamentos de Vieira $(1996$, p. 9) que relata:

É característico das calhas de chumbo do século XII e XIII, fundidas na lingoteira, a alma espessa e a aba curta bem como os perfis regulares e sem rebarbas...

Quando as calhas eram demasiado finas para enfatizar o efeito pretendido, o vitralista cercava-as com um traço de grisalha. Mas além desta solução, havia a dobragem de calhas de chumbo, introduzindo entre elas uma vareta de osso. "Tanto a dimensão como as espessuras das calhas de chumbo evoluíram paralelamente ao desenvolvimento de outras técnicas, adquirindo com a invenção da fiera, no século XV, um perfil mais longo e fino. (VIEIRA, 1996, p. 9) 


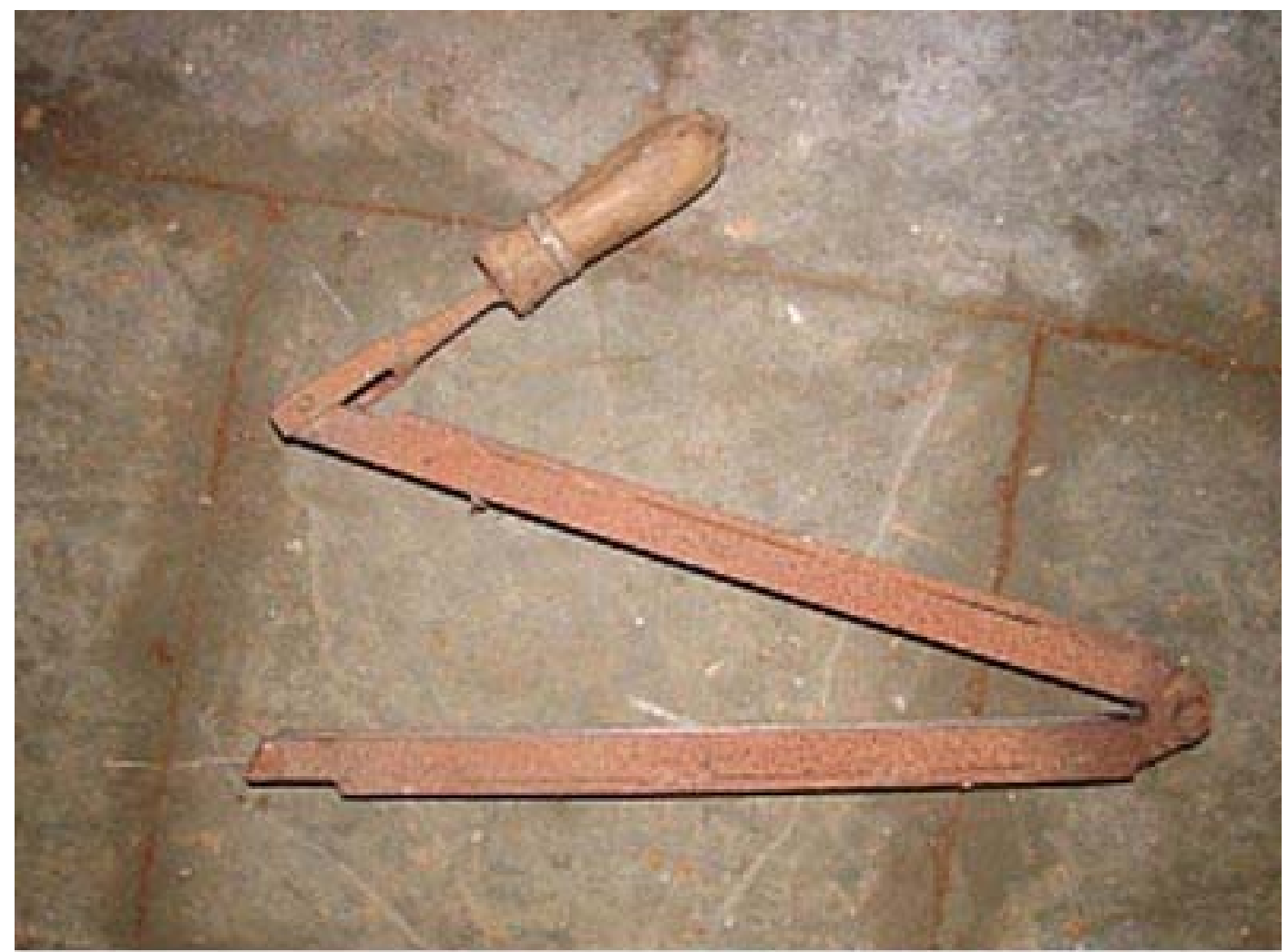

FIGURA 7 - Exemplo de uma ligoteira (espólio Casa Genta). Fonte: autora, dezembro/2008.

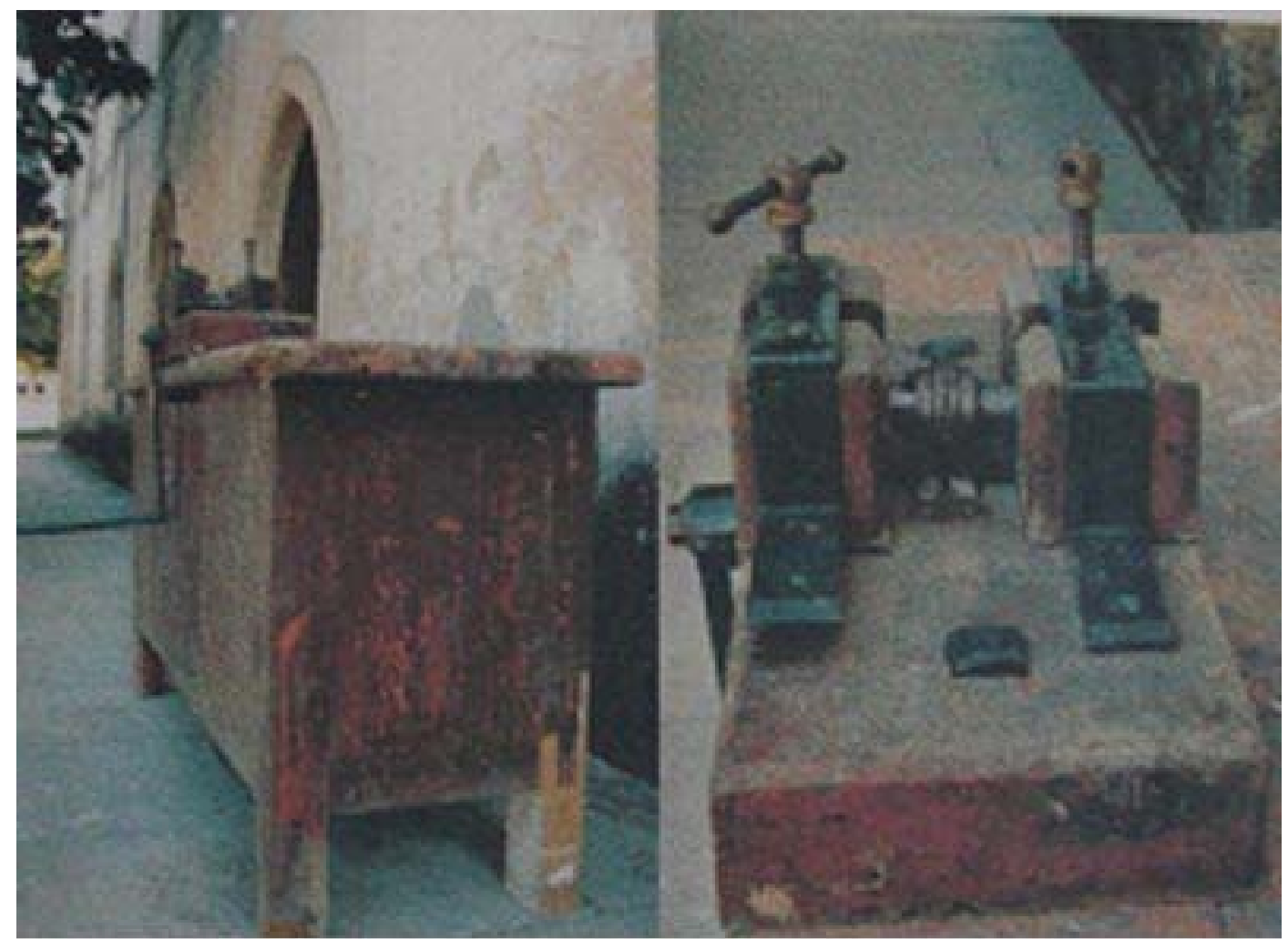

FIGURA 8 - Exemplo de fieira manual. Fonte: autora, em 1996. 


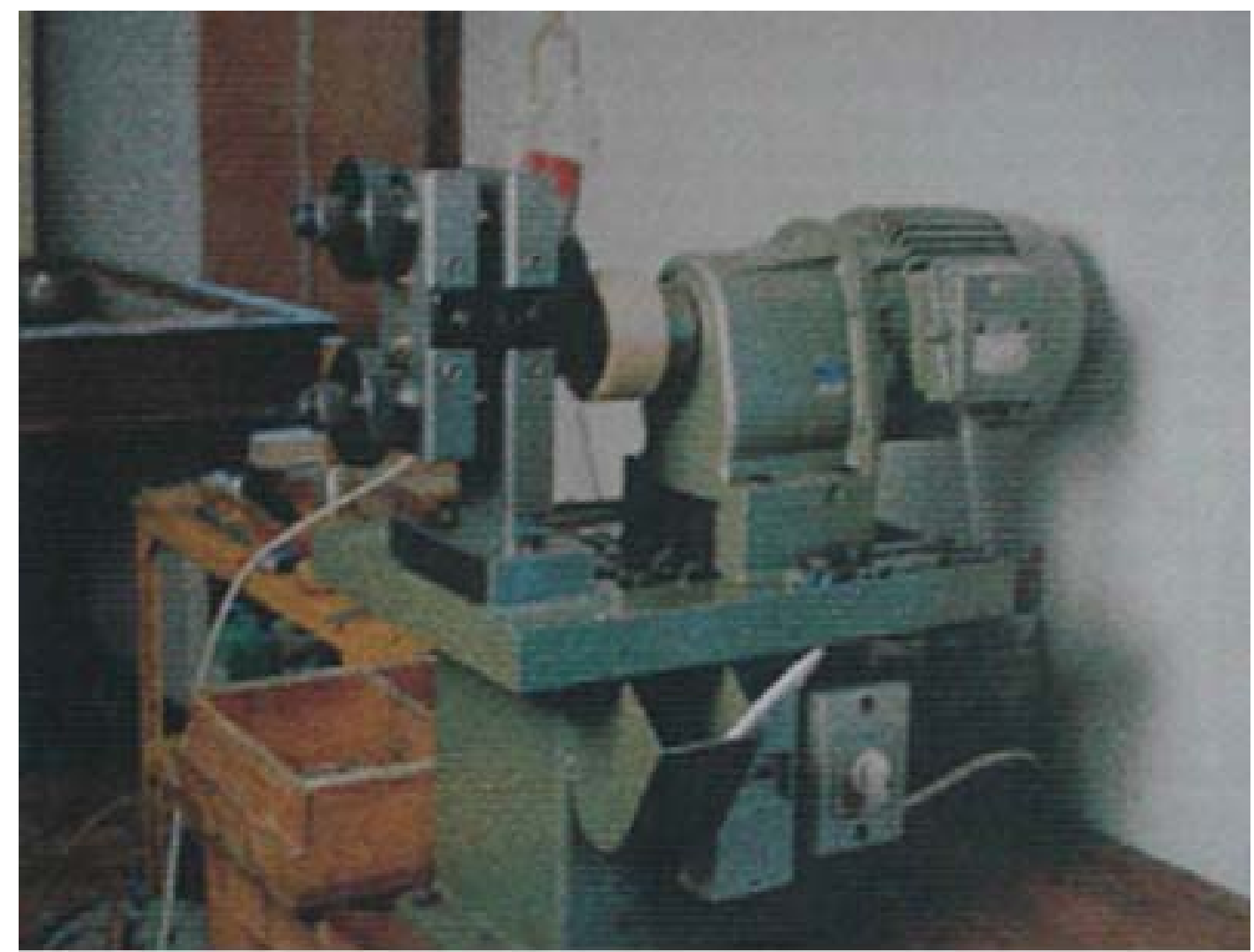

FIGURA 9 - Exemplo de fieira elétrica.Fonte: autora, em 1996.

As calhas metálicas fabricadas no século 20 eram de chumbo-estanho, obtidas em fieiras, a maioria, existentes nos próprios ateliês. Segundo registros encontrados no ateliê Casa Conrado, a liga de chumbo e estanho vinha da Europa e no próprio ateliê era aquecida e passada na fieira para dar a forma $\mathrm{H}$ e o tamanho da aba e alma que se necessitasse. Também, no levantamento do espólio do ateliê Casa Genta, em posse do vitralista Ruan Motta, residente em Porto Alegre, verifica-se que o referido ateliê possuía fieiras próprias e, inclusive, uma pequena perfiladeira manual que permitia o ajuste de desenhos especiais da aba (Figura 10) conforme registrado nos vitrais da $12^{\mathrm{a}}$ Regional do IPHAN de Porto Alegre. 


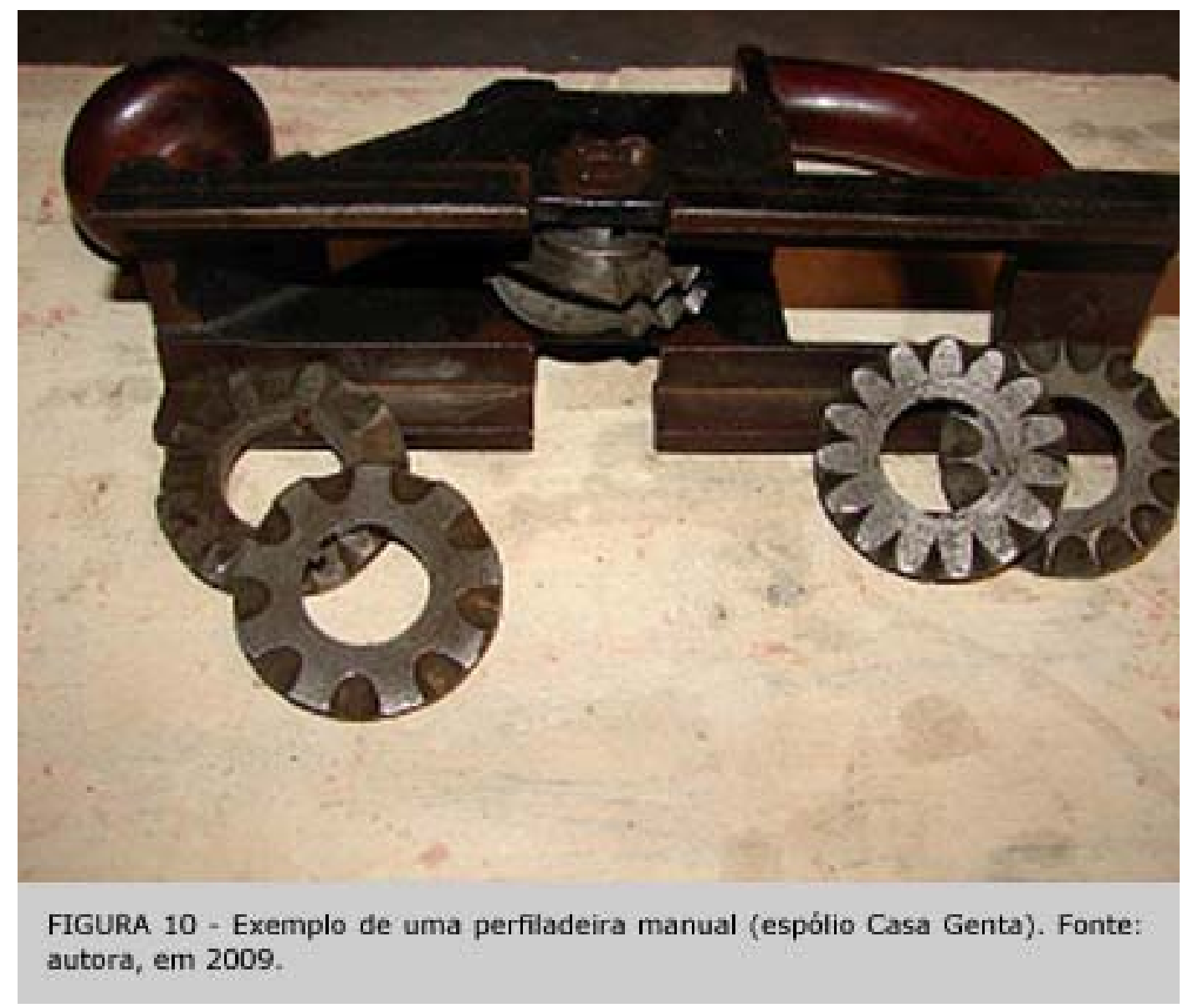

Escolher os lugares de corte e de aplicação da calha de chumbo é fundamental para um bom projeto, tanto em termos de estabilidade como de estética. É pela definição da trama metálica que permeia todo o vitral que pode-se ter a definição do volume e das zonas críticas de esforços do próprio peso da estrutura. Estruturas metálicas muito próximas também são prejudiciais, pois podem alterar ou prejudicar a organização dos desenhos.

Após a delicada e trabalhosa tarefa de pintura e queima dos vidros ocorre a montagem dos vitrais. Na execução desta etapa, bastante artesanal, a prática é o suficiente para uma boa desenvoltura. Normalmente a montagem é feita em uma sala separada porque precede ao trabalho de calafetagem, que também se caracteriza com bastante sujidade.

A montagem é sempre feita a partir de uma extremidade do painel. Na mesa costuma-se colocar o desenho das peças e sobre ele, com a ajuda de uma espátula, os fragmentos de vidro, de forma e tamanhos variados, e a calha metálica são 
encaixados para compor o painel. Completada a montagem e conferidas as dimensões exatas do painel, baixa-se as abas das calhas e estas são soldadas. Tradicionalmente, se faz uso do fogo direto para soldar as calhas, como é o caso do ateliê Cantuária (Inglaterra), que ainda usa este processo. No entanto, no século 20, a partir do desenvolvimento da indústria metal-mecânica soldas metálicas de baixo ponto de fusão passaram a ser aplicadas com ferros de soldar nas zonas de intersecção das calhas. O processo de soldagem é feito no anverso e reverso do painel. Nesta etapa deve-se cuidar para que as soldas fiquem uniformes e regulares sendo ainda usado em alguns casos, como o aplicado no ateliê na Casa Conrado, um líquido oxidante para escurecer a solda. (MELLO, 1996, p. 157).

Após a soldagem é feita a calafetagem com uma massa a base de óleo de linhaça, gesso crê e secante, que é espalhada pelo painel penetrando na interface do vidro com a calha. Esta operação garante a firmeza do vidro e a impermeabilidade do vitral. A colocação do painel no vão deve ocorrer somente após a secagem da massa de calafetagem.

Para os painéis de grandes dimensões é necessário a inserção de uma caixilharia (armação), porque as calhas metálicas de junção não apresentam resistência mecânica e se deformam facilmente. Nestes casos, pela tradição, normalmente, usam-se barras metálicas de ferro colocadas externas ao vitral. Estas são barras colocadas sobre o painel travadas por pontos de soldas no vitral e pelas extremidades que ficam fixas nos próprios vãos. As barras de fixação são espécies de travas que impedem o deslocar do conjunto, e as deformações tão comuns nos vitrais.

\section{Considerações finais}

Quando se fala em vitral é impossível deixar de pensar no tempo, na memória e na transmissão de conhecimento de gerações para gerações.

A arte vitral trata da formação de um tipo de manifestação cultural construída pelo tempo e a partir da repetição. Trata-se, portanto, de um processo de memória e tradição que se transforma e, ao mesmo tempo, carrega algo do passado em sua 
existência. Algo que para ter continuidade, necessitou de transformações e adaptações às novas realidades, quer pelo tempo quer pelo espaço (Europa-Brasil).

O fazer da arte vitral vincula-se diretamente à construção de uma identidade sóciocultural feita a partir de tradições europeias oriundas da Idade Média. Por isto, podese dizer que a produção do vitral, repetitiva e continuada, testa diretamente seu vínculo a conceitos de tradição integrada a um processo inacabado de criação e recriação.

$\mathrm{Na}$ Europa a arte vitral possui uma representação cultural, visto que suas origens marcam uma manifestação cultural fortemente divulgada e vinculada com grande parte da historia da manifestação artística medieval. No Brasil a presença da arte vitral é menor, pontual, e está diretamente vinculada à imigração de europeus.

De qualquer modo, quando se fala em tradição, buscam-se vínculos com manifestações identitárias de grupos sócio-culturais, independente de seu tamanho e valores étnicos e simbólicos.

Tratar a arte vitral como um saber de tradição que pela sua transmissão geracional histórico cultural tem uma grande importância na questão do patrimônio imaterial e seu valor intrínseco se faz urgente para a salvaguarda deste saber, tendo em vista que os condicionantes da cultura contemporânea não favorecem a sua manutenção e projetam um término em sua existência.

\section{Notas}

(1) Este artigo foi publicado em PAIVA, Raquel; BARBALHO, Alexandre (Orgs.). Comunicação e cultura das minorias. São Paulo: Paulus, 2005.

(2) Artigo publicado em PAIVA, Raquel; BARBALHO, Alexandre (Orgs.). Comunicação e Cultura das Minorias. São Paulo: Paulus, 2005

(3) Instrumento em forma similar a uma caneta que é usado para corte de vidro. A partir de um risco feito pela ponta que lubrificada gira marcando a linha de separação dos fragmentos. 
(4) Segundo CUNHA Antônio G., Dicionário etimológico Nova Fronteira da língua portuguesa, Rio de Janeiro: Nova Fronteira, 1999, p. 400, guilda é uma associação típica da Idade Média entre as corporações de operários, negociantes, artesãos ou artistas.

(5) Conforme Aurélio Buarque de Holanda Ferreira. Aurélio século XXI: o dicionário da língua portuguesa. Rio de Janeiro: Nova Fronteira, 1999, p. 608, Decalcar consiste em reproduzir (um desenho) comprimindo-o de encontro a uma superfície; calcar.

(6) Conforme definição no glossário de WERTHEIMER, M., Estudo do patrimônio de vitrais produzidos em Porto Alegre no período 1920-1980, CD-ROM, 2009, o Cartão é um desenho em tamanho natural de uma composição ou figura que serve de modelo a uma obra realizada em pintura, mosaico ou vitral.

(7) Diego Pufal é genealogista e familiar dos antigos donos da Casa Genta. Troca de correspondência durante o ano de 2009, em Porto Alegre.

(8) WERTHEIMER, M., Estudo do patrimônio de vitrais produzidos em Porto Alegre no período 1920-1980, CDROM, 2009.

(9) Segundo registros do glossário de WERTHEIMER, M., Estudo do patrimônio de vitrais produzidos em Porto Alegre no período 1920-1980, CD-ROM, 2009, fierias é uma máquina composta por duas rodas de ferro dentadas, a $2 \mathrm{~mm}$ de distância uma da outra, com umas chumaceiras pelas quais passam as barras de chumbo para se obter a medida desejada.

\section{Referências bibliográficas}

ARÉVALO, J. M. La tradición, el patrimonio y la identidad. [S.I.: s.n.], 2001. Disponivel em: <http://www.dip_badajoz.es/publicaciones/reex/.../estudios_02_rcex_3_2004.pdf>. Acesso em: maio 2010.

BRANDÃO, I. L. Luz no êxtase: vitrais e vitralistas no Brasil. São Paulo: Dorea Books and Art, 1994.

BRISAC, C. A thousand years of stained glass. London: Chartwel Books, 1986.

CANDAU, Joel. Antropología de la memoria. Buenos Aires: Nueva Visión, 2002.

COUTINHO, Eduardo Granja. Os sentidos da tradição. In: PAIVA, Raquel; BARBALHO, Alexandre (Orgs.). Comunicação e cultura das minorias. São Paulo: Paulus, 2005.

CUNHA, Antônio Geraldo da. Dicionário etimológico Nova Fronteira da língua portuguesa. Rio de Janeiro: Nova Fronteira, 1999.

FERREIRA, Aurélio Buarque de Holanda. Aurélio século XXI: o dicionário da língua portuguesa. Rio de Janeiro: Nova Fronteira, 1999. 
MELLO, Regina L. Silveira. Casa Conrado: cem anos de vitral brasileiro. Dissertação (Mestrado em Artes)Universidade Estadual de Campinas, Campinas, 1996.

MORRIS, Elizabeth. Stained and decorative glass. New Jersey: Chartwell Books, 1987.

ORNELLAS, Sandro. As malhas do tempo identitário. Inventário, Revista dos estudantes do Programa de PósGraduação em Letras e Linguística da UFBA, João Pessoa, ago. 2003. Disponível em: $<$ http//www.inventario.ufba.br/01/01sornellas.htm>. Acesso em: jun. 2010

PAIVA, Raquel; BARBALHO, Alexandre (Orgs.). Comunicação e cultura das minorias. São Paulo: Paulus, 2005.

VIEIRA, Sérgio. História do vitral. Curso de Conservação e Restauro de Vitrais, Batalha (Portugal), 1996. (Promovido pelo IPPAR - Instituto Português do Patrimônio Arquitectónico e Arqueológico). Material didático mimeografado.

WERTHEIMER, M. Estudo do patrimônio de vitrais produzidos em Porto Alegre no período 1920-1980. Porto Alegre, 2009. CD-ROM.

\section{Créditos}

* Arquiteta, mestranda do Programa de Pós-Graduação Mestrado em Memória Social e Patrimônio Cultural da Universidade Federal de Pelotas-RS.

e-mail: arqmw@uol.com.br

** Engenheira civil, doutora em engenharia de materiais, docente do Programa de Pós-Graduação Mestrado em Memória Social e Patrimônio Cultural da Universidade Federal de Pelotas-RS.

e-mail: margareteg@ufpel.edu.br;

artigo recebido em 08/2010

artigo aprovado em 01/2011 